\title{
Experiences of amateur athletes' non-participating entourage at participatory sport events
}

\begin{abstract}
The proliferation of participatory sport events is attracting scholarly attention, with extant research primarily focusing on profiling participants, and understanding participants' experiences. The experiences and perspectives of those who travel to participatory sport events to support competing athletes, the 'non-participating entourage' (NPE), have largely been overlooked. This stakeholder group is arguably under-recognised by those staging participatory sport events. The purpose of this study was to explore NPE experiences at participatory sport events, adopting a phenomenological approach and employing stakeholder theory as an interpretive lens. Qualitative interviews were conducted with 21 NPE of amateur athletes in Australia. Findings highlighted that NPE provide emotional and logistical support to their athlete at events. However, while providing support, NPE also experienced positive and negative emotions arising from contextual factors including their relationship to the athlete, group composition, athlete performance, and event design and conditions. This research highlights a vexed, though crucial stakeholder relationship between NPE and event management organisations, requiring unique stakeholder management strategies.

Keywords: Participatory sport events; amateur athletes; non-participating entourage; stakeholder theory.
\end{abstract}




\section{Experiences of amateur athletes' non-participating entourage at participatory sport events}

\section{Introduction}

Participatory sport events catering for amateur athletes, such as marathons, triathlons, open water swims, and adventure races, have burgeoned in popularity (Crofts, Schofield, \& Dickson, 2012; Murphy, Lane \& Bauman, 2015). Crofts et al. (2012) described such events as 'community-based open entry events that require participants to engage in moderate-to-high levels of energy expenditure' (p. 149), while Lamont and Jenkins (2013) described participatory sport events as 'organised sporting events, open to all, and in which participation ... is promoted over competition in and of itself' (p. 394). Extant research on participatory sport events has been dominated by efforts to understand participant perspectives, for example, what motivates amateur athletes and the benefits athletes gain through participation (Lamont \& Kennelly, 2012), how athletes engage with event locations (Hinch \& Holt, 2017), and factors contributing to athlete satisfaction (Theodorakis, Kaplanidou, \& Karabaxoglou, 2015). Substantial preparation is required to develop the fitness necessary to complete participatory sports events (McCarville, 2007), particularly longer events that test participants' endurance. Consequently, researchers (i.e., Clarke, 2017; Lamont, Kennelly \& Moyle, 2017) have begun to examine the potential impacts of event preparation on athletes' spouses and others close to athletes. However, Lamont et al. (2017) noted that researchers have largely overlooked the role and experiences of the "nonparticipating entourage' (NPE), or those who support amateur athletes at events. An athletes' NPE may include their spouse, children, parents, other family members, or friends.

We argue that the event experiences of NPE warrants attention for several reasons. First, the audience at participatory sport events is largely comprised of athletes' NPE, who contribute 
to event atmosphere through their attendance and provision of support. Consequently, NPE are an important stakeholder group for event management organisations (hereafter, 'event organisers') to consider during event design and delivery. Second, sport tourism research has highlighted how participatory sport events can attract travelling athletes, who may travel to events with NPE (Hallman \& Wicker, 2012; Hinch \& Holt, 2017; Lamont et al., 2012). Hence, NPE can be significant contributors to the economic and social impacts of events on host destinations. For these reasons, athletes' NPE warrant the attention of event organisers and researchers.

The purpose of this research was to explore the experiences of NPE who have attended participatory sport events to support an amateur athlete. We adopted a phenomenological approach in order to investigating the lived experiences of NPE during their attendance at events. Further, drawing upon stakeholder theory (Freeman, 1984), we sought to enhance understandings of NPE as a stakeholder group of event organisers and to highlight areas for future research.

\section{Literature Review}

\section{Amateur athletes, NPE, and participatory sport events}

Involvement in participatory sport events must be understood in two inseparable temporal contexts: the day-to-day context where athletes 'train' to develop physical fitness for upcoming events; and the event context, in which they put their physical preparation to the test (Lamont, Kennelly, \& Wilson, 2012; Lamont et al., 2017). Atkinson (2008) described how serious amateur athletes adhere to a habitus characterised by highly structured day-to-day lifestyles, bouts of 'intense athletic suffering' (p. 169), and difficulty balancing life as an athlete with other 
responsibilities. Maintenance of this habitus can also be taxing to an athlete's family (Lamont et al., 2017; McCarville, 2007).

Spousal and familial support can be intrinsically important to amateur athletes (McCarville, 2007), as well as being a facilitator or constraint to involvement in participatory sport events (Kennelly, Lamont, \& Moyle, 2013). In a study of amateur triathletes by Lamont et al. (2012), respondents acknowledged their involvement in triathlon could strain their spousal and familial relationships by reducing quality time spent together, and increasing the domestic and child-care responsibilities of their partner. Recently, Lamont et al. (2017) explored the perspectives of amateur athletes' spouses, and found that support partners endure challenges including increased child-care and domestic responsibilities, and forfeiting their own leisure time whilst their athlete prepares for events.

While studies on the day-to-day context of amateur athletic careers are now emerging, scant research has addressed the experiences of those who support amateur athletes in event contexts. One exception is Clarke (2017). When Clarke completed his first Ironman, his girlfriend penned a piece describing her experience as a supporter (Martin, 2011). She suggested participants often do not 'appreciate the emotional toll it takes' to watch a loved one complete a physically demanding event (Martin, 2011, non-paginated). She described feeling 'useless,' 'tense,' 'lonely,' and 'cold, wet and tired' while waiting on the side-line for Clarke to pass. She explained that during an event, 'Not knowing where your racer is, is hard to accept - and there's nothing you can do about it' (Martin, 2011, non-paginated). In contrast, she described how relieving and uplifting it was to witness him finish. She concluded, 'I've learned that for racer and supporter Ironman brings a unique concoction of bonding and separation' (Martin, 2011, non-paginated). 
Martin's (2011) piece exposed a ‘fertile area of study' to Clarke (2017, p. 1). Clarke analysed the supporter experiences of three female spouses of amateur Ironman triathletes who described providing support as 'hard work' (p. 4), dominated by 'intense anticipation' (p. 5), the need to stay in position to see athletes pass, and relief and 'controlled release' (p. 6) when smiles or other forms of acknowledgement were exchanged with their athlete. However, Clarke (2017) reflected that his research raised 'more questions than answers' (p. 1), including questions around what event organisers do (if anything) to provide for athletes' supporters.

In their study of ultramarathon runners, Hinch and Holt (2017) called for research looking beyond the experiences of participants to other participatory sport event stakeholders, specifically volunteers and 'non-competing entourage' (p. 1095). They argued it is important to understand the potentially divergent experiences of these stakeholders, as 'from a tourism perspective, these groups are also critical determinants to the success and sustainability of the event' (p. 1095). Indeed, Saayman and Saayman (2012) suggested the economic contribution of NPE at participatory sport events could be significant. Their study of the 2011 Comrades Marathon in South Africa suggested 10,140 South African competitors were each accompanied on average by one supporter, while 1,277 international competitors were each accompanied on average by 0.8 supporters. However, Saayman and Saayman (2012) acknowledged that open and dispersed event layouts make it difficult to quantify, and accurately capture the full economic contribution of NPE at participatory sport events.

The importance of illuminating NPE perspectives is further suggested by a study of participatory sport event organisers (Kennelly, 2017) which found organisers had two primary concerns: (1) designing positive and satisfying event experiences for athletes; and (2) effectively managing logistics to deliver successful events (as evaluated by athletes). It is therefore arguable 
that if event organisers focus on athletes and overlook the needs of other event stakeholders (i.e., $\mathrm{NPE}$ ), they may fail to create an experience that is engaging for all attendees. Hence, bringing to light the perspectives of NPE on their event experiences may help improve knowledge on how to accommodate this stakeholder group.

\section{Stakeholder theory}

Stakeholder theory contends that the survival and success of an organisation is contingent upon its ability to produce value and agreeable outcomes for stakeholders (Freeman, 1984; Mitchell, Agle, \& Woods, 1997). Stakeholders are broadly defined as any individual or group who can influence the operations of an organisation (Freeman, 1984), or who may be affected by the 'actions, decisions, policies, practices or goals of the organisation' (Merrilees, Getz, \& O’Brien, 2005, p. 1063). Proponents of stakeholder theory argue that managers should continually monitor an organisation's operating milieu, to identify and respond to the varying needs, goals, and expectations of stakeholders (Freeman, 1984). These tenets clearly translate into an event context: to remain viable, events must produce value for and serve the evolving needs of their stakeholders. Simultaneously, event organisers have a responsibility to identify and minimise the potential for any harm to their stakeholders (Lamont \& Kennelly, 2018), including NPE.

Stakeholder theory has been used in management research in different ways (Donaldson \& Preston, 1995). Normative uses of the theory suggest how managers should behave toward stakeholders (Clarkson, 1995), while instrumental interpretations of stakeholder theory are used to 'identify the connections, or lack of connections, between stakeholder management and the achievement of traditional corporate objectives' (Donaldson \& Preston, 1995, p. 71). This latter 
vein of stakeholder research is 'unabashedly strategic' (Laplume, Sonpar, \& Litz, 2008, p. 1158) and suggests careful management of stakeholders' interests could be advantageous to an organisation's performance. While normative applications of stakeholder theory regard the interests of all stakeholders as intrinsically significant, instrumental interpretations accept that due to finite resources, organisations may not be able to accommodate all stakeholders (Mitchell et al, 1997). Hence, advocates of instrumental stakeholder theory suggest organisations should strive to achieve mutually beneficial relationships where possible, particularly with their most salient stakeholders (Mitchell et al., 1997).

Stakeholder theory was deemed a suitable lens through which to interpret the experiences of NPE for three reasons. First, past research has advocated use of stakeholder theory for examining management facets of both major sport events (Merrilees et al., 2005; Parent, 2008; 2016), and participatory sport events (Batty, Cuskelly, \& Toohey, 2016). For example, Batty et al. (2016) examined stakeholder perspectives of participatory sport event sponsorship by soft drink, confectionary and fast food companies. Their research sought viewpoints from event owners, managers, the sponsors themselves, organisations supplying event volunteers, corporate teams, local government, a recipient charity, and associated sport organisations. They found that some participatory sport event stakeholders were prepared to wield their social influence if they disagreed with the sponsors chosen by event organisers (i.e., to agitate for change). They suggested if event organisers ignored such stakeholder concerns, the financial viability of their events may be compromised (i.e., large corporate teams may withdraw from involvement with the event).

Second, in researching the marketing of a major sport event, Merrilees et al. (2005) advocated stakeholder theory as a 'useful theoretical tool' for understanding 'less traditional' 
organisational relationships (p. 1074). The relationship investigated in this research could be considered 'less traditional' in that interaction between event organisers and NPE is typically mediated by athletes (who are paying customers of the event), with minimal (if any) direct contact. Stakeholder theory therefore helps explain why, despite lack of direct contact, NPE may still warrant the attention of event organisers for moral and strategic reasons. Finally, we deemed stakeholder theory a suitable lens through which to interpret the experiences of NPE as the theory acknowledges that impacts can be bi-directional between an organisation and its stakeholders. Hence, in examining the experiences of athletes' NPE at participatory sport events, we draw upon normative and instrumental interpretations of stakeholder theory to elucidate why NPE are a salient stakeholder, why event organisers should cater for NPE, as well as why such actions may be strategically important.

\section{Methods}

\section{Research design and sampling}

A flexible and inclusive epistemological approach was desirable to examine the experiences of NPE at participatory sport events, as it was recognised NPE perspectives could be diverse, influenced by individual circumstances and unique event factors. We adopted a phenomenological approach for this research (Sokolowski, 2000), following tourism and leisure studies deploying interpretive epistemologies which embrace subjectivity, relativity, and facilitate empathetic accounts of lived experiences (Fendt, Wilson, Jenkins, Dimmock, \& Weeks, 2014). Fendt et al. (2014) advocated Heideggerian (interpretive) phenomenology, as it 'values the researcher's own understandings and experiences, viewing them as a crucial tool for interpretations of the experiential descriptions' (p. 402). All four authors have experience as both 
athletes competing in, and NPE attending participatory sport events. We therefore acknowledge our subjectivities shaped conceptualisation of the research and interpretation of informants' narratives, although our experiences arguably enabled a deep, empathetic engagement with our informants (Sparkes, 2002).

To address our research aims we utilised purposive sampling. Interviewees had to meet our definition of NPE: an athlete's spouse, child, parent, other family member, or close friend, who had attended at least one participatory sport event in support of their athlete. Additionally, each NPE's athlete had to exhibit a consistent pattern of participation in participatory sport events (at least one event per year, for at least two years), with a history of investing significant time in physically training for such events.

Accessing NPE proved challenging, hence we employed four methods for recruiting interviewees. First, we emailed a promotional infographic to running and triathlon clubs across Australia, which proved unsuccessful. We then approached NPE in attendance at a major triathlon event in Queensland, Australia in September 2015 to recruit participants for follow-up interviews. This yielded seven interviews. We then sought participants through personal social world networks, such as the authors' running or triathlon clubs/groups. We contacted known NPE directly and requested fellow athletes promote our study to their NPE. Finally, interviewees were asked to promote our study to other persons in their social networks who may fit our purposive selection criteria. These initiatives yielded an additional 14 interviews.

In total, 21 interviews were conducted between September 2015 and September 2016. Approaching 21 interviews, no significant new findings were emerging and we deemed it appropriate to cease data collection. A combination of phone, Skype, and face-to-face interviews were conducted, with conversations lasting between 25 and 60 minutes. Participants completed a 
brief demographic questionnaire contextualising their athlete's event participation. Although a schedule guided each interview, in keeping with our phenomenological approach, conversations were left flexible to explore issues most germane to each interviewee (Denscombe, 2010). Participants were questioned around the kinds of support they provide their athlete at events; their recollections of experiences at past events; how they decide whether or not to attend events; and their perceptions around whether or not event organisers adequately cater for athletes' NPE.

The characteristics of the sample are presented in Table 1. Pseudonyms are used to conceal the identity of interviewees, and to comply with the ethical approval granted for this research. The sample was dominated by athletes' spouses $(\mathrm{n}=15)$, but also included adult children ( $\mathrm{n}=2)$, parents $(\mathrm{n}=3)$ and one close friend. Of the 15 interviewees who identified themselves as an athlete's spouse, 14 had two or more children with their athlete. The majority of respondents were female $(\mathrm{n}=15)$, although the sample also included six male spouses. The interviewees' athletes competed in numerous ( $\mathrm{n}=2$ to $20+$ ) participatory sport events per annum, including triathlons, running events, open water swims and adventure races. Athletes contested events of varying lengths and levels of challenge, however, most were engaged in arduous events such as marathons or ultra-running and long-distance triathlons.

\section{Insert Table 1 here}

\section{Data analysis and trustworthiness of the research}

Data analysis commenced whilst data collection was ongoing. Interviews were transcribed verbatim and analysed to inform and refine subsequent interviews. Upon cessation of data collection, a final, detailed analysis was performed. Given our desire to explore the 
experiences of NPE using stakeholder theory, data were analysed twice according to the following protocols. Firstly, data were examined through the theoretical lens of stakeholder theory to identify evidence on the role of NPE at events. Our aim here was to build an understanding of NPE as stakeholders of event organisers, thus the data were interrogated to establish if and how NPE could influence an event and/or the operations of event organisations, as well as how NPE may be affected by the business practices of event organisations. Secondly, data were inductively analysed to gain understanding of NPEs' event experiences, with particular reference to the range of emotions characterising their experiences.

Neuman's (2011) coding process of open, axial, and selective coding was utilised to reduce raw data into major thematic categories for both rounds of analysis outlined above. Open coding involved scanning data for broad themes. This produced an initial framework of codes which were then refined during the subsequent axial coding phase, which entailed a detailed rereading of interview transcripts. Selective coding then involved searching for thematic patterns within the data, such as potential inter-relatedness between emergent codes. Two authors coded the data, and met to compare coding lists before the whole team agreed on a final coding schema and the major thematic categories presented in the next section.

Trustworthiness in qualitative research is concerned with verifying that researchers' reconstructions of interviewees' accounts are a truthful reflection of reality (Merriam, 1998). Researcher subjectivity is inherent in qualitative research (Lincoln \& Guba, 1985). As declared earlier through our personal experiences as amateur athletes and as NPE, we acknowledge that this study constituted 'insider research' in which the researchers possessed 'knowledge of the organisation and/or phenomenon prior to the study's commencement' (Hays \& Singh, 2012, p. 140). Our positions as insiders enabled more intimate understandings of NPE experiences than 
'outside' researchers (Sparkes, 2002), and we reiterate that interpretive phenomenology values the researcher's experiences to unpack informants' experiential accounts (Fendt et al., 2014).

Nevertheless, we adopted several measures as advocated by Hays and Singh (2012) to reduce the influence of researcher subjectivity. Through continuous processes of collective and self-reflexivity, we encouraged each other to periodically consider if and how our individual experiences may be shaping the data collection and analysis. All researchers were involved in conducting interviews, reducing the potential that one researcher's world view would dominate decisions on lines of questioning and interpretations of data. While two members of the research team coded data, the whole team discussed and agreed on the final coding schema to enhance the trustworthiness of our reconstructions. Member checks were also performed whereby interviewee's transcripts were emailed to them for review, although no changes were requested (Creswell, 2015).

\section{Findings}

Results are presented in two sections reflecting major thematic categories. The first section focuses on the actions of NPE at participatory sport events. Specifically, analysis revealed interviewees perceived they held key roles providing emotional and logistical support to their athlete. In order to provide support, NPE endeavored to monitor their athlete's location throughout events. Interviewees with children also functioned as a family organiser, coordinating support and child-care on event day. The second section focuses on favourable and less favourable emotional aspects of interviewees' experiences at events. These include camaraderie, enjoyment of a positive atmosphere, excitement, inspiration, a sense of pride and gratification, as 
well as anxiety, frustration, and resentment. Each of these themes are described with supporting evidence below.

\section{Actions of NPE at participatory sport events}

\section{Emotional support}

Many interviewees described providing emotional support to athletes before, during, and after events. Emotional support encompassed being present on event day, cheering, encouraging, and assisting athletes to manage anxiety. For example, Aaron (spouse) focused on assisting his wife calm pre-event nerves: 'It was such a big thing for her, I think she needed help with it.' Jill (parent) explained in relation to her son, 'I think having me there - it just settled him right down.' In contrast, if Robbie (spouse) saw his wife walking during an event, he offered encouragement 'to give [her a] verbal kicking up the arse.' Interviewees like Zoe (friend) felt the provision of emotional support was important to athletes like her friend: 'she always talks about how good it is to have the support out on the track.'

\section{Logistical support}

Logistical support included monitoring hydration and nutrition pre-event, preparing athletic equipment, providing transport to and from the event, and being positioned on the event course to supply athletes with items (i.e., nutrition and clothing) during a race. Jan (spouse) described how pre-event she would 'watch what [her husband] is eating and [ensure he's] eating all the right things. It's like constantly, 'Have you drunk this amount today?' Similarly, Melissa (parent) explained on event day, 'I get the food ... I have to make sure that she's got the right snacks in her bag'. Heidi (spouse) explained when attending 'logistically difficult' events, it was her responsibility to 'get there really early and get all the [equipment] sorted out.' Lyndal 
(spouse) provided logistical support to her husband during an adventure race, and found the experience 'intense ... if you weren't in the right place at the right time it was a little stressful.' Sometimes interviewees were chided by their athlete if something did not go to plan: 'there's one particular occasion, we mistimed quite badly one of his stops and let's just say it still gets brought up a lot' (Lyndal, spouse).

\section{Athlete monitoring}

Many interviewees spoke of needing to monitor their athlete's progress during an event for two reasons. First, knowing and being able to access an athlete's position was necessary for NPE to provide emotional and logistical support. Additionally, as discussed later, being able to track an athlete's progress connected to NPEs' emotional experiences at events, specifically managing anxiety about their athlete's well-being.

Interviewees discussed a range of strategies to monitor athletes during an event. In some instances, event organisers supplied athlete tracking equipment that enabled NPE to follow their athlete's progress online or via a smartphone application. Others were able to track their athlete's smartphone or GPS watch, if they were carried during the event. However, such technologies were impractical in locations where mobile phones lacked reception or Internet connection. At one remote race, Sally (spouse) explained her husband was 'out of range most of the time' and consequently 'it was a bit hard to track where he was.'

In the absence of tracking technologies, interviewees had to estimate their athlete's position based on their athlete's predicted race pace. Belinda (spouse) described this as having to 'guesstimate,' and for some NPE it was a source of stress. Rebecca (spouse) described an experience of waiting for her husband at an event: 'I have no way of getting in contact with him. Eventually he did come through, but I was starting to get a bit panicky.' Effective 
'guesstimating' was also important for Aaron when cheering on his wife: '[I had to] try and get the timing right, because the kids aren't going to hang around for half an hour with nothing to do’.

However, interviewees highlighted how athlete tracking technologies and mobile phone reception did not always guarantee a smooth supporter experience. Heidi (spouse) described how an event in Melbourne was 'difficult ... because it started and finished in different places and it was in the city, so you were having to get around.' Consequently, several interviewees (i.e., James and Heidi) expressed a preference for attending smaller events that were easier to navigate with compact course routes. Heidi (spouse) found targeting events held in smaller, regional towns made athlete monitoring easier: 'Often those little [events] ... literally the whole town is just turned over to the triathlon and you can walk around from transition to where the swim is to where the bikes come in. So it's quite easy to get about.'

\section{Family organiser}

NPE with children also enacted the roles of child-care provider and family coordinator. The majority of interviewees had attended events with children, which necessitated they keep children fed, entertained and comfortable through extraordinary event conditions including early morning starts; heat, cold and rain with no shelter; in 'chaotic' and 'busy' crowds (Aaron, spouse); and across large geographical areas. These conditions produced challenges for NPE, and at times became deterrents to event attendance:

Often if there's rain, it doesn't work well. Parking is a nightmare. Food, water, shelter, all of those things you've got to think about when you've got toddlers and we tend to just, by default, avoid those kinds of situations (Aaron, spouse). 
Some NPE spoke of the challenges of keeping children entertained during long participatory sport events: 'you've got to entertain them. They don't want to just stand and watch people come past' (Belinda, spouse). Aaron (spouse) noted, 'They like seeing mum come past, but they don't like all the waiting around for mum to come past', while Heidi (spouse) mused that waiting could be incomprehensible for young children: 'I think it's just a hard concept ... they do get annoyed.'

Jan (spouse) recalled one overwhelming experience of caring for children solo during an event. Her husband took their car to the event, leaving her with their children and no vehicle: I had to get a cab ... I had a portacot, a stroller with four really little kids and our luggage. And we had to walk. And then by the time we got to where the car was parked, I didn't have car keys ... I had one of the kids in a backpack and one in a pouch at the front and one in a stroller and one hanging on to the stroller, at the end of the race, trying to find him.

Despite challenges, some NPE, such as Shawn (spouse), were committed to being there for the athlete no matter how grim the conditions:

It was freezing cold and [we had] raincoats on... We had to calculate when she was going to be at what point so we would get the kids something warm and dry and then come back out into the rain when she'd come past and cheer her on.

Having presented data conveying the roles enacted by NPE, we now turn attention to data expressing their lived experiences at participatory sport events. 


\section{Characteristics of NPEs' experiences at participatory sport events}

Positive aspects of NPEs' experiences at events

Camaraderie. The sense of camaraderie amongst supporters was nominated by several interviewees as one of the most enjoyable aspects of events. Camaraderie arose from cheering for athletes, meeting other supporters, children 'putting their hand out to get high fives' (Zoe, friend), and event commentators 'hyp[ing] up the crowd' (Debby, parent). Debby explained, 'I'm one of those people that yell at all of the strangers ... because they all have their names on [their race bib].' Rebecca (spouse) spoke of feeling 'part of it' whilst cheering on her husband:

Those events are, on the whole, a really good vibe. To have all the people that you end up chatting to around you, cheering on the people that you know, you cheer on the people they know. I think it's a very positive - overwhelmingly positive experience.

Enjoyment of positive atmosphere. Several interviewees described how they enjoyed the positive atmosphere at events, irrespective of the challenges they experienced. For example, Jan (spouse) found 'everybody is happy to be there and everybody is quite positive,' while Melissa (parent) described how she embraced the eclectic event experience: 'There's so much colour and there's happiness, there's sadness ... It's just one of those environments that you either love or hate and I [have] learned to absolutely love it and embrace it.' Similarly, Adrian (spouse) stated: 'I love it. I love the atmosphere at all these events ... There's always a positive. You might be stressing [about] the kids at times, but I love the events.'

Excitement. Interviewees also described the excitement of events, for example: 'The atmosphere [at Ironman events] is just electric. Very exciting. The way they hype everything up

for the full Ironman is just absolutely spectacular' (Debby, parent). Shawn (spouse) described the added excitement of travelling when he supported his wife during a triathlon festival in north 
Queensland: 'You are away from your normal routine. Everyone there is excited and looking forward to it.'

Inspiration. Interviewees commonly reported feeling inspired at events. Rebecca (spouse) recounted, 'I love watching all these people of all shapes and sizes and walks of life challenging themselves that way ... you just go, "wow, it's an inspirational thing to do".' Ben (spouse) described how he enjoyed watching athletes achieve their goals and felt that spectating would have a positive influence on his children:

I love being around that environment ... Seeing a whole lot of people at the top of their game running and pushing the limits. Like some people didn't think they would be able to do it and then they crossed the line. The kids had seen that, so it's pretty cool. Similarly, Sally (spouse) derived inspiration from the hard work of participants: 'These people are just amazing because they work so hard. Sometimes people get injured and they still make it.'

Sense of pride and gratification. Interviewees frequently described experiencing pride and gratification on event day. For example, Melissa (parent) described experiencing 'a lot of pride' when her daughter completed an event: 'it wasn't really about winning. It was about the participation and how much fun she had, seeing her fulfill that dream.' Sally (spouse) commented on her husband competing: 'I actually get quite emotional. Especially when he crosses the finish line. I'm so happy that he did it.' For other interviewees, witnessing their athlete's pride was gratifying. Jemma (spouse) enjoyed witnessing her husband being 'very proud of himself to finish the race.' In addition, she mentioned her children's pride in their father's achievements: 'The girls go up and give him big cuddles, "well done Daddy!"” 
Similarly, Catrina (spouse) said of her children: 'They were really proud of him, like really proud.'

Many interviewees framed their pride and gratification in terms of the extensive preparatory effort and goals of their athlete. For example, Ben (spouse) spoke of feeling elated watching his wife complete an event: 'I get pretty emotional towards the end of it. Just because you can see how happy she is ... she's achieved what she wanted to achieve, especially if she gets like a PB [personal best] time ... I'm stoked for her.' These comments may also be interpreted as implying a degree of relief on the part of NPE when their athletes perform well in an event.

\section{Negative aspects of NPEs' experiences at events}

Anxiety. Alongside positive event experiences, interviewees identified a range of negatives, with anxiety being a strong theme. Many interviewees, discussed feeling anxious, nervous, worried, stressed, or even scared during events. For example, watching their children compete in challenging events was difficult for parents Melissa and Jill. Melissa described feeling 'really wound up,' while Jill recalled, 'your heart's in your mouth the whole time.' Interviewees' anxiety largely arose from concern for their athlete's wellbeing. Lyndal (spouse) described experiencing 'high nerves' when watching her husband run marathons:

I was always worried when he did a marathon that he would do that - you know, like you see on the TV the people who go into that kind of spasmodic shock at the end. That was always my fear.

Heidi (spouse) held similar fears and recounted her husband's first Ironman event: 
I didn't enjoy it. I was just really worried about him because that was the first time he had done the full distance and it just seemed like a ridiculous thing to do just in terms of distance, and, I think the first year he did Noosa (Triathlon) someone died on the run. Interviewees' concerns could be exacerbated by unfavourable event conditions. For example, Melissa (parent) was worried about her daughter competing on days when the ocean was rough: 'If the surf's big I get really upset ... I don't want her out there.' The challenge of keeping track of athletes during events compounded some interviewees' stress, particularly if the athlete did not come through course checkpoints when anticipated: 'you have no way of getting in touch with them or finding out if something has happened to them' (Heidi, spouse). For some NPE, anxieties evoked through their athlete's participation were a deterrent from attending events, however, as Jill (parent) explained, she would experience anxiety whether she was there or waiting at home:

I'm there as a support for the events, even though I'd much rather not be anywhere near them because I worry so much about him. Then again, if you're there you worry, if you're not there you worry so you may as well be there so that you can help if something happens.

Frustration. Some interviewees reported feeling frustrated whilst supporting their athlete on event day, largely due to the challenges of finding athletes, navigating difficult event precincts, and in many cases, managing young children. Aaron (spouse) described a 'wild goose chase' driving around with toddlers on the verge of 'meltdown' to support his wife during one event, concluding 'it was such an anti-climax!' Rebecca (spouse) spoke of a frustrating experience at a running festival in Sydney, with road closures, 'nightmare' parking, and 'a huge amount of people.' She felt a 'responsibility' to support her husband, however, recounted that 
attending events with her children could be challenging and unenjoyable. Consequently, if she felt an event was not 'accessible ... for families,' she would choose not to attend. Aaron (spouse) concluded longer participatory sport events were frustrating from a supporter's point of view:

It's just like they're not set up for the spectator ... You're just there to either collect or cheer or keep out of the way as much as possible. [Events are] going to be mostly hard work. They're hard for the athlete, but it's a whole big deal for the supporters too.

Finally, Danielle (child) and Vanessa (child) felt frustrated for entirely different reasons. Danielle's father raced an Ironman on her $18^{\text {th }}$ birthday, while Vanessa (child) described missing social opportunities because she felt obliged to attend events to support her father.

Resentment. Several interviewees expressed bitterness at missing out on their own opportunities to train for and compete in events, as their partner's event commitments seemed to take priority. For example, Belinda (spouse) and her husband were both involved in triathlon, but she felt her husband's involvement took precedence over hers: 'I'm incredibly grateful that he was out there doing it...but there were times that I went hang on, this is my turn and you're out here again!' Similarly, Aaron (spouse) spent hours waiting for his wife on the sidelines of marathons and triathlons and had relinquished his involvement in running to look after their children:

You feel a little bit of an outsider, because everyone else is just so into their running thing and it's all everyone ... wants to talk about. It makes you feel a bit bad about yourself I think going to events like that ... [But] we can't both really do it simultaneously, because we've got kids to look after. 


\section{Discussion}

This research examined experiences of athletes' NPE at participatory sport events to shed light on the stakeholder relationship between NPE and event organisers. In this section, we discuss why NPE are a stakeholder of event organisers for normative and instrumental reasons. In addition, we conclude by identifying areas for future research, specifically around five variables emerging from our analysis that appear to shape the experiences of NPE at participatory sport events.

\section{NPE as stakeholders of participatory sport events}

Our findings demonstrate that an athletes' NPE are a legitimate stakeholder of participatory sport event organisers. Stakeholders are parties that can impact an organisation, or be impacted upon by the organisation's actions (Freeman, 1984). These definitional conditions, particularly the latter, were evident in the data. Our findings demonstrate that NPE experience positive and negative emotions on event day which, in part, are shaped by event organisers' practices such as course and precinct layout, accessibility, event communications, and provision of amenities and services (e.g., availability of toilets, seating, shade, food and beverage services, entertainment for children). Further, NPE may contribute to the success of events through coconstruction of event atmosphere and provision of logistical and/or intangible support to participants. Alternatively, our findings indicate that NPE may exercise agency and not attend events if they perceive conditions to be challenging or unpleasant, thereby reducing the potential social and economic impacts of an event on its host destination. These bilateral impacts are elaborated upon below. 
Resonating with findings of previous research (Clarke, 2017; Lamont et al., 2012; McCarville, 2007), data demonstrated that partaking in a participatory sport event can be a significant undertaking for participants and their NPE alike. Lamont et al. (2017) illustrated the substantial impact an athlete's pre-event preparation could have on their spouse, who may willingly or unwillingly tolerate stressors such as increased domestic responsibilities and subordination of their own leisure interests in the lead up to an event. Our findings suggest similar impacts exist for NPE in the event context. While respondents described a range of positive aspects to supporting athletes on event day, our research also highlighted negative experiences NPE endured at events. Stressors included difficulties managing young children; event precincts that were challenging to navigate; lack of appropriate services and amenities; and, as found by Clarke (2017), anxiety arising from concerns for their athlete's wellbeing.

Proponents of stakeholder theory advocate that organisations should accommodate the varying needs, goals and expectations of their stakeholders (Freeman, 1984). However, expectations around stakeholder management vary according to normative or instrumental interpretations of the theory. According to normative stakeholder theory (Donaldson \& Preston, 1995), event organisers should consider the needs of NPE simply because they are a legitimate stakeholder. That is, NPE are impacted upon by event organisers' actions, at times negatively. Therefore, according to this normative perspective, event organisers are obliged to consider their impact on NPE for ethical reasons irrespective of whether event organisers consider NPE a priority or not. This reasoning echoes suggestions by Lamont and Kennelly (2018) that partaking in extreme forms of participatory sport events, could 'result in harm to participants and those close to them,' especially an athlete's spouse and family (p. 2). They proposed: 
Event management organisations should not be immune from conducting their business in ethical and socially responsible ways. Event management organisations have a broad range of direct and indirect stakeholders that may withstand the worst of their entrepreneurial and profit-driven business practices (p. 11).

Our findings affirm that NPE experience stressors at events. We therefore suggest it would be desirable for socially responsible event organisers to lessen stressors through careful event design. However, our findings also suggest it could be strategically advantageous to consider NPE a vital stakeholder group in planning for events.

A criticism of stakeholder theory is that it is unrealistic for organisations with finite resources to accommodate all parties qualifying as stakeholders (Mitchell et al., 1997). Consequently, researchers advocating instrumental stakeholder theory suggest identifying how mutual benefits can be realised between the organisation and strategically important stakeholders (Laplume et al., 2008). We suggest NPE are a strategically important stakeholder group for event organisers as they provide critical emotional and logistical support to athletes, as well as cocreating the event atmosphere through their presence and cheering. This clearly has implications for event organisers, as athletes are their key paying customers. Indeed, it is possible that the NPE's support and experiences at events may influence athletes' feelings towards an event and their decision to return. Although more research is required, we also hypothesise it is possible for NPE to constrain an athlete's participation in events that are difficult for supporters to attend or enjoy. Consequently, we suggest catering for NPE could improve both NPEs' and athletes' experiences, and their likelihood of revisiting an event, which in turn may affect the event's profitability and sustainability. 
Second, the attendance of NPE may help bolster the economic and social contribution of an event to a host destination (Getz, 2013; Hinch \& Holt, 2017), making it more attractive to local authorities, tourism providers, and other destination stakeholders. NPE may spend on accommodation, meals, and local entertainment, compounding the economic impacts of an event (Saayman \& Saayman, 2012). The volume of NPE attending is therefore significant, as the injection of new money into a local economy remains a core metric through which the success and ongoing viability of many events are determined (Getz, 2013). Both our findings and past research (Hallman \& Wicker, 2012; Hinch \& Holt, 2017; Lamont et al., 2012) indicate that athletes may couple sport event participation with a family holiday. However, NPE may not always be willing to devote their leisure time to a potentially unpleasant supporter experience. Therefore, participatory sport events that are designed with supporters in mind may be more successful in attracting active sport tourists and their NPE.

Event researchers have emphasised the importance to event goers of the social aspects of event experiences (Chalip, 2006; Lamont, 2014; Shipway, King, Lee, \& Brown, 2016). Permeating our findings was the notion of communitas, evident in themes such as camaraderie, enjoyment of a positive atmosphere, and excitement. Chalip (2006) defined communitas as 'an energy that can be shared by all,' wherein 'social rules and social distinctions seem less important ... There is a heightened sense of community among those who are present' (p. 110). Our findings indicate that, for NPE, experiencing the sense of community was an appealing feature of participatory sport events, and conversely that NPE are critical to the co-creation of communitas through their interactions with other NPE on the sidelines. These findings resonate with studies of spectators at major professional cycling events such as the Tour de France (Lamont, 2014; Shipway et al., 2016) which demonstrated that spectators' collective roadside 
practices led to the production of communitas within liminal spaces celebrating shared values around their sport.

An event's unique circumstances shape its design and delivery; hence it is not possible to suggest a definitive list of strategies event organisers may employ to enhance the social aspects of their events. Feedback from NPE on specific events would be required. However, data from interviewees suggested it could help if participatory sport events were designed with a central event site to concentrate the provision of spectator services (i.e., toilets, food and beverage outlets, shelter, entertainment, parking and updates on athlete progress etc.). A course that regularly intersected a central site would also reduce the need for NPE (especially with small children) to move, and if auxiliary services, communal seating and entertainment were provided to keep spectators on-site, the positive social experiences arising from the sense of community could be maximised. Centralising the provision of services for NPE could also reduce the costs of catering for this group to event organisers and could even create opportunities to derive income from this traditionally revenue-neutral stakeholder group. However, the unique characteristics of each event will determine what is possible, and we suggest that seeking and responding to feedback from NPE on specific event social features could translate into a source of competitive advantage for event organisers.

While it seems clear that NPE are a salient stakeholder of event organisers, our findings highlight how, from the perspective of some NPE, their stakeholder relationship with event organisers is vexed. Some interviewees suggested their needs were overlooked in the design of events, producing anxious and frustrating experiences. We hypothesise that a potential source of dissonance in the event organiser-NPE stakeholder relationship may be that event organisations are often profit-seeking businesses. As 'no entry fee is asked for spectators' (Saayman \& 
Saayman, 2012, p. 227) at participatory sport events, event organisers are unlikely to extract significant revenue from NPE. In some instances, event organisers may actually incur costs catering for this group (e.g., by needing to segregate supporters from participants and roads for safety reasons with temporary fencing/barricades). For profit-driven event organisers, finding ways to simultaneously increase the value proposition for NPE, while deriving revenue from NPE may incentivise better management of this stakeholder group.

A further potential source of incongruity is that the event organiser-NPE stakeholder relationship is brokered by athletes as paying customers of an event. When athletes register for an event, organisers collect their details for event communications. Further, while organisers may give athletes the opportunity to provide post-event feedback, none of our interviewees indicated that event organisers had solicited their feedback. Event organisers are therefore reliant upon athletes as intermediaries in conveying event information to NPE, and vice versa, which may hamper event organisers' communication efforts. Without access to feedback from NPE, it may be difficult for event organisers to fully understand and manage this important stakeholder group.

In summary, participatory sport event organisers must juggle both revenue-positive athletes and revenue-neutral (sometimes revenue-negative) NPE as stakeholder groups. Our findings suggest event organiser-NPE stakeholder relationships are not always effectively managed and that a nuanced approach to stakeholder management is required, given organisers are typically reliant on athletes to channel communications to NPE. However, it is clear there remains much work to be done in exploring conditions shaping NPE experiences at participatory sport events. 


\section{Experiences of NPE at participatory sport events: Avenues for future research}

Our findings illustrate that NPE are not a homogenous group, and that event day experiences could vary considerably. However, our analysis suggested five broad variables influencing how NPE evaluate and assign personal meaning to their experiences at participatory sport events: (1) the NPE's relationship to the athlete; (2) the support role(s) enacted by NPE; (3) the NPE's group composition; (4) the athlete's performance, and (5) event destination, design, and conditions. We contend that in combination, these variables influence the range of emotions that NPE experience at events. Further, the variables, and the emotions they elicit, may influence whether NPE willingly attend future events, or whether their support is reduced or withdrawn. The variables, the interplay between them, and suggestions for future research are elaborated upon below.

In the data, athletes' spouses and parents were more likely to mention stress and anxiety than athletes' friends and children. This raises questions around the potential for differences in the emotional experiences of NPE according to their relationship (type and level of closeness) with the athlete. A related consideration is the nature of NPE's support role on event day. Our findings signaled NPE provided both emotional and logistical support with varying degrees of willingness. Interviewees comments highlighted there may be disparities between athletes' expectations regarding the support their NPE will provide, versus the support NPE is willing and/or able to render. Hence, future research incorporating a larger sample of different 'types' of NPE (e.g., spouses, children, friends) could consider the impact on their event experience of their relationship to the athlete and concomitant expectations around the support role they (willingly or unwillingly) enact. Such research is germane to event organisers who may require different strategies to cater for this non-homogenous group. 
Relatedly, our findings highlight that providing support to athletes was challenging for spouses attending events with small children. Hence, the NPE's group composition warrants further attention from sport tourism researchers who may consider who attends events with active sport tourists and their interwoven experiences of the event and destination. Such research could have applied implications for event organisers and other destination stakeholders (e.g., local tourism operators, sponsors, retailers, entertainers) who may aid in informing NPE about local attractions and services catering for children. Further, while our research included male and female parents/spouses attending events with children, more females were represented. Evidence suggests the registrations of many participatory sport events are skewed towards male participants (e.g., Carter, 2015), a trend reflected in broader literature addressing active sport tourism (Gibson, Lamont, Kennelly, \& Buning, 2018). This may provide fertile ground for leisure researchers, as it raises gender-related questions around access to leisure. Indeed, studies of leisure have long been concerned with the role of women as enablers of men's leisure (e.g. Boyle \& McKay, 1995; Bray, 1983) and our findings suggest these remain pertinent avenues for critical scholarly inquiry. Our findings also highlight the need for future research to examine division of child-care responsibilities in enabling event participation, and what happens when one partner's leisure needs are subjugated by their spouse's.

The NPE's supporter experience may also vary according to athlete performance. Our findings indicate that an athlete's performance may appreciably impact on their NPE. Poor performance could elicit disappointment and concern for the athlete, while successful performance could result in celebration and pride. Another consideration highlighted by respondents was the impact of the athlete's performance expectations. Allen-Collinson and Hockey (2007) suggested that after long periods of dedicated and structured training, athletes can 
experience a period of 'the blues' post-event, or in the case of injury. This potentially means an unsatisfactory performance (as defined by the athlete) could escalate from a source of disappointment on event day, to a range of deeper negative emotions over ensuing weeks, to which NPE may be further subjected. Future research could examine the impact of performance expectations on the leisure careers of amateur athletes and concomitantly their NPE.

Finally, event destination, design and event day conditions encapsulates characteristics of the event offering, ranging from the attractiveness and features of the chosen event destination, to the weather and event's design (e.g., layout of event precinct, provision shelter in case of adverse weather, ease of access, availability of parking or public transport, services available, options for tracking or knowing an athlete's location, and entertainment for children). It is through this variable that event organisers have greatest capacity to influence NPE experiences as our findings signify that event design and conditions enable or conspire against NPEs' efforts to provide support and manage children. As participatory sport events are unique, case study research may be required to examine the effectiveness of different event designs for supporters. Further, sport tourism researchers could consider how event destination characteristics may influence NPEs' choices to attend, and in turn influence athletes' selection of events.

Overall, we suggest the interplay between the above variables will be unique for each individual, and in combination will influence NPE's emotional experience at events. We also acknowledge that the impact of each variable relative to the other variables may differ according an individual's circumstances. Hence, greater understanding of each of these variables and how they interact could aid event organisers in designing and delivering more attractive events and in deploying more effective strategies for engaging and managing NPE as a salient stakeholder group. 


\section{Conclusion and limitations}

This research elucidates the experiences of NPE at participatory sport events, and in doing so endorses NPE as a stakeholder group worthy of consideration by event organisers for normative and instrumental reasons. The stakeholder relationship between NPE and event organisers requires nuanced stakeholder management approaches as it is brokered by athletes, potentially vexed, and commonly overlooked in terms of the impacts both parties may evoke for each other. NPE in this research described the support roles they undertake for participating athletes at events, and in doing so highlighted a range of factors that enable or challenge their execution of these important roles. NPE also described a spectrum of emotions they experienced, from positives associated with communitas at the event site and pride in their athletes' performance, through to negatives such as anxiety and frustration.

Our research suggested NPE's experiences arose from interplay between five variables, which in combination produce a unique event experience for each individual. NPE should not be treated as a homogenous group, but rather a group whose diverse characteristics and emotions combine to co-construct an event's atmosphere, with flow-on implications for the event's success. At the broadest level, the most important implication flowing from this research is that event organisers should make strategic efforts to better understand the needs of NPE attending their events, with a view to improving their experiences. Event organisers should consider initiatives catering for NPE such as providing shelter; adequate food and beverage services; child-friendly spaces and/or activities; and event precinct layouts that are easy for spectators to navigate whilst also facilitating vantage points for NPE to view their athlete. 
While this research represents a foundational effort to improve knowledge on NPE and their significance to participatory sport events, we found, similar to Clarke (2017), that our work raised many questions for future research. In addition to aforementioned future research suggestions arising from the five variables, several limitations in the current study present avenues for further investigation. Specifically, a limitation of this research is that it lacks the perspectives of athletes and event organisers. Combining the perspectives of athletes, their NPE and event organisers in one study could help elucidate the tensions between their varying needs and expectations, and the challenges of producing agreeable outcomes for all. While our findings indicate that at times NPE felt their needs were overlooked by event organisers, research is required to determine if this contention is supported from event organisers' perspectives. In addition, there are many permutations of participatory sport events, with some events longer, more geographically disperse and physically arduous than others. We therefore acknowledge the NPE experience may vary according to the type (length or physical intensity) of event. However, a challenge faced in our research was that many of the NPE's athletes competed in events of varying lengths (i.e., from 'sprint' to Ironman triathlons) and thus NPE shared experiences across diverse event formats. While future research could delineate specific 'types' of participatory sport event to examine differences in NPE experience, we suggest it may be more practical for event organisers to focus on understanding how unique facets of their own event design may positively or negatively impact on NPE supporting athletes.

To conclude, we suggest that given the burgeoning popularity of participatory sport events, greater understanding of NPE experiences is essential for event organisers and researchers concerned with understanding leisure and tourism experiences. Specifically, we 
suggest knowledge on NPE experiences could improve event organisers' capacity to cater for this group, and in turn improve the sustainability and delivery of participatory sport events. 


\section{References}

Allen-Collinson, J., \& Hockey, J. (2007). 'Working out' identity: Distance runners and the management of disrupted identity. Leisure Studies, 26(4), 381-398.

Atkinson, M. (2008). Triathlon, suffering and exciting significance. Leisure Studies, 27(2), 165180.

Batty, R., Cuskelly, G., \& Toohey, K. (2016). Community sport events and CSR sponsorship: Examining the impacts of a public health agenda. Journal of Sport and Social Issues, $40(6), 545-564$.

Bray, C. (1983). Sport, capitalism, \& patriarchy. Canadian Woman Studies, 4(3), 12-14.

Boyle, M., \& McKay, J. (1995). 'You leave your troubles at the gate': A case study of the exploitation of older women's labor and 'leisure' in sport. Gender and Society, 9(5), 556575.

Carter, K. (2015, April 21). Marathons by the numbers: Running the data. The Guardian. Retrieved from https://www.theguardian.com/lifeandstyle/the-runningblog/2015/apr/21/marathons-by-numbers-running-the-data.

Chalip, L. (2006). Towards social leverage of sport events. Journal of Sport and Tourism, 11(2), 109-127.

Clarke, D. W. (2017). Understanding event sport tourism experiences of support partners: A research note. Leisure Sciences. Advanced online publication. Retrieved from doi.org/10.1080/01490400.2017.1384942

Clarkson, M. B. E. (1995). A stakeholder framework for analysing and evaluating corporate social performance. Academy of Management Review, 20(1), 92-117. 
Crofts, C., Schofield, G., \& Dickson, G. (2012). Women-only mass participation sporting events: does participation facilitate changes in physical activity? Annals of Leisure Research, 15(2), 148-159.

Creswell, J. W. (2015). 30 essential skills for the qualitative researcher. Sage Publications, London: UK.

Denscombe, M. (2010). The good research guide for small-scale social research projects $\left(4^{\text {th }}\right.$ ed.). Berkshire, UK: McGraw Hill.

Donaldson, T., \& Preston, L. (1995). The stakeholder theory of the corporation: Concepts, evidence and implications. Academy of Management Review, 20(1), 65-91.

Fendt, L., Wilson, E., Jenkins, J., Dimmock, K., \& Weeks, P. (2014). Presenting phenomenology: Faithfully recreating the lived experiences of Surfer Girls. Annals of Leisure Research, 17(4), 398-416.

Freeman, R. E. (1984). Strategic management: A stakeholder approach. Marshfield, US: Pitman.

Getz, D. (2013). Event tourism: Concepts, case studies, and research. Putnam Valley, NY: Cognizant Communication.

Gibson, H., Lamont, M., Kennelly, M., \& Buning, R. (2018). Introduction to the special issue, active sport tourism. Journal of Sport \& Tourism, 22(2), 83-91.

Hallman, K., \& Wicker, P. (2012). Consumer profiles of runners at marathon races. International Journal of Event and Festival Management, 3(2), 171-187.

Hays, D., \& Singh, A. (2012). Qualitative inquiry in clinical and educational settings. New York: The Guilford Press.

Hinch, T. \& Holt, N. (2017). Sustaining places and participatory sport tourism events. Journal of Sustainable Tourism, 25(8), 1084-1099. 
Kennelly, M. (2017). 'We've never measured it, but it brings in a lot of business': Participatory sport events and tourism, International Journal of Contemporary Hospitality Management, 29(3), 883-899.

Kennelly, M., Lamont, M., \& Moyle, B. (2013). Constraint negotiation in serious leisure: A study of amateur triathletes. Journal of Leisure Research, 45(4), 466-484.

Lamont, M. (2014). Authentication in sports tourism. Annals of Tourism Research, 45, 1-17.

Lamont, M., \& Jenkins, J. (2013). Segmentation of cycling event participants: A two-step cluster method utilising recreation specialisation. Event Management, 17(4), 391-407.

Lamont, M., \& Kennelly, M. (2012). A qualitative exploration of participant motives among committed amateur triathletes. Leisure Sciences, 34(3), 236-255.

Lamont, M., Kennelly, M., \& Moyle, B. (2017). Perspectives of endurance athletes' spouses: A paradox of serious leisure. Leisure Sciences. Advanced online publication. Retrieved from doi.org/10.1080/01490400.2017.1384943

Lamont, M., Kennelly, M., \& Wilson, E. (2012). Competing priorities as constraints in event travel careers. Tourism Management, 33(5), 1068-1079.

Lamont, M., \& Kennelly, M. (2018). Sporting hyperchallenges: Health, social and fiscal implications. Sport Management Review. Advanced online publication. Retrieved from doi.org/10.1016/j.smr.2018.02.003

Laplume, A. O., Sonpar, K., \& Litz, R. A. (2008). Stakeholder theory: Reviewing a theory that moves us. Journal of Management, 34(6), 1152-1189.

Martin, A. (2011, September 27). His first Ironman, 220Triathlon, Retrieved from http://www.220triathlon.com/news/his-first-ironman/5194.html 
McCarville, R. (2007). From a fall in the mall to a run in the sun: One journey to Ironman triathlon. Leisure Sciences, 29(2), 159-173.

Merriam, S. (1998). Qualitative research and case study applications in education. San Francisco, CA: Jossey-Bass.

Merrilees, B., Getz, D., \& O’Brien, D. (2005). Marketing stakeholder analysis: Branding the Brisbane Goodwill Games. European Journal of Marketing, 39(9), 1060-1077.

Mitchell, R. K., Agle, B. R., \& Woods, D. J. (1997). Towards a theory of stakeholder identification and salience: Defining the principle of who and what really counts. Academy of Management Review, 22(4), 853-886.

Murphy, M., Lane, A., \& Bauman, A. (2015). Leveraging mass participation events for sustainable health legacy. Leisure Studies, 34(6), 758-766.

Neuman, W. L. (2011). Social research methods: Qualitative and quantitative approaches. $\left(7^{\text {th }}\right.$ ed.). Boston, MA: Allyn and Bacon.

Parent, M. (2008). Evolution and issue patterns for major sport event organising committees and their stakeholders. Journal of Sport Management, 22(2), 135-164.

Parent, M. (2016). Stakeholder perceptions on the democratic governance of major sport events. Sport Management Review, 19(4), 402-416.

Saayman, M., \& Saayman, A. (2012). The economic impact of the Comrades Marathon. International Journal of Event and Festival Management, 3(3), 220-235.

Shipway, R., King, K., Lee, I. S., \& Brown, G. (2016). Understanding cycle tourism experiences at the Tour Down Under. Journal of Sport \& Tourism, 20(1), 21-39.

Sokolowski, R. (2000) Introduction to phenomenology. Cambridge, UK: Cambridge University Press. 
Sparkes, A. (2002). Telling tales in sport and physical exercise: A qualitative journey. Champaign, IL: Human Kinetics.

Theodorakis, N., Kaplanidou, K., \& Karabaxoglou, I. (2015). Effect of event service quality and satisfaction on happiness among runners of a recurring sport event. Leisure Sciences, $37(1), 87-10$. 